\title{
The Use of Cavitation Peening to Increase the Fatigue Strength of Duralumin Plates Containing Fastener Holes
}

\author{
Hitoshi Soyama \\ Department of Nanomechanics, Tohoku University, Sendai, Japan \\ Email: soyama@mm.mech.tohoku.ac.jp \\ Received 1 March 2014; revised 12 April 2014; accepted 30 April 2014 \\ Copyright (C) 2014 by author and Scientific Research Publishing Inc. \\ This work is licensed under the Creative Commons Attribution International License (CC BY). \\ http://creativecommons.org/licenses/by/4.0/ \\ (c) (i) Open Access
}

\section{Abstract}

An effective method for improving the fatigue life of Duralumin plates with fastener holes, such as those used in the construction of aircraft, is to introduce a compressive residual stress around the fastener holes. Cavitation peening is a novel peening method that uses the cavitation impact produced when a high-speed water jet is injected into a water-filled chamber. In this paper, Duralumin plate specimens with holes were treated by cavitation peening under various conditions, and the fatigue strength of the specimens was determined using a plate bending fatigue test. It was revealed that a compressive residual stress was introduced not only on surfaces perpendicular to the axis of the cavitating jet but also on the walls of holes which were parallel to this. It was found that a 51\% improvement in fatigue strength could be achieved by cavitation peening. Note that this is first report demonstrating an improvement in the fatigue life of Duralumin plates with fastener holes by cavitation peening.

\section{Keywords}

Fatigue, Fastener Hole, Duralumin, Cavitation Peening, Residual Stress

\section{Introduction}

The development of fatigue cracks around fastener holes in aircraft components is a serious problem that affects the life of these components. However, the introduction of a compressive residual stress around the fastener holes, for example by cold expansion [1], can improve the fatigue life. Laser peening has also been proposed for this purpose [2]-[5]. Peening methods that use the cavitation impact induced by the shock waves that arise when bubbles collapse [6], known as “cavitation shotless peening” or “cavitation peening”, have previously been pro- 
posed for enhancing the fatigue life of various materials [7]-[9].

In cavitation peening, the cavitation bubbles are generated by injecting a high-speed water jet into a waterfilled chamber through a nozzle. Cavitation clouds shed periodically from the nozzle and spread out across the surface being treated, and when the bubbles collapse they produce impacts which can deform the material [10]. A cavitating jet can be used to treat surfaces set parallel to the jet axis [11] and also introduce compressive residual stress at depth beneath the surface [12]. Thus, it may be possible to use such a jet to treat the surfaces of the walls of fastener holes. The surface roughness produced by cavitation peening is less than that produced by shot peening [13], and the chemical cleaning required to remove iron stuck to the Duralumin plate after shot peening is not needed after cavitation peening. As cavitation peening can also improve the fretting fatigue strength of Ti-6Al-4V [14], the number of applications for cavitation peening would increase if it could be demonstrated that the fatigue strength of plates with holes could be improved.

As is well known, cavitation is a hydrodynamic phenomenon [6], in which both the development and collapse of cavitation bubbles are affected by the shape of the surface being treated. Although the cavitating regions around hydrofoils or impellers can be obtained by numerical simulation, quantitative simulation of the cavitation impact cannot be done. Thus, an experimental study of the effects of cavitation peening on holes needs to be done. A relatively low pressure plunger pump with an injection pressure of $30 \mathrm{MPa}$ is sufficient for this purpose [15]. The expensive plunger pumps normally used for water jet cutting and peening [16] [17] are not required in this case. Recently, a fourfold increase in the aggressive intensity of a cavitating jet using a newly developed nozzle was successful demonstrated [18]. It was proposed to use this new nozzle for the experiments done in this work.

Plate bending fatigue tests were used to measure the fatigue strength of specimens consisting of Duralumin plates with fastener holes before and after cavitation peening. Since the main factor in improving the fatigue strength by peening is the introduction of compressive residual stress, the residual stresses at the surface of the plates and in the walls surrounding the holes were evaluated by an X-ray diffraction method.

\section{Experimental Facilities and Procedures}

Figure 1 shows a schematic diagram of the peening system utilizing a cavitating jet [18]. The cavitating jet is produced by injecting a high-speed water jet into a water-filled chamber, i.e., tank A. The test water is stored in tank B and pressurized by a plunger pump with a maximum pressure of $35 \mathrm{MPa}$ and a maximum discharge of $3.0 \times 10^{-2} \mathrm{~m}^{3} / \mathrm{min}$. In order to avoid suction vortices, a floating plate is placed near the nozzle. After the cavitation bubbles collapse, residual bubbles [19] remaining in the test water are recirculated. These residual bubbles give rise to a cushion effect that reduces the shock wave produced by cavitation bubbles collapsing. Thus, a partition plate is placed in tank B to eliminate these. Figure 2 shows a test nozzle equipped with an optimized cavitator and an optimized guide pipe for the cavitating jet [18]. The geometrical parameters of the nozzle are given in Table 1. The cavitator feeds cavitation nuclei to the nozzle plate where the main cavitation is produced, and the guide pipe increases the size of the cavitation cloud. The cavitator and guide pipe enhance the aggressive intensity of the cavitating jet by about a factor of four [18]. In the present experiment, the injection pressure $p_{1}$ was $30 \mathrm{MPa}$ and the standoff distance from the upstream end of the nozzle plate to the surface of the specimen was 262 mmas shown in Table 2. These conditions are the same as those used in previous work [18].

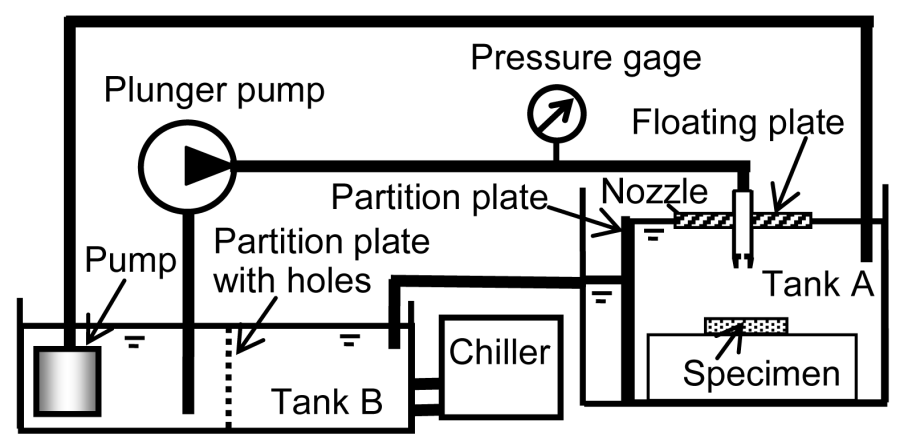

Figure 1. Schematic diagram of the cavitation peening system. 


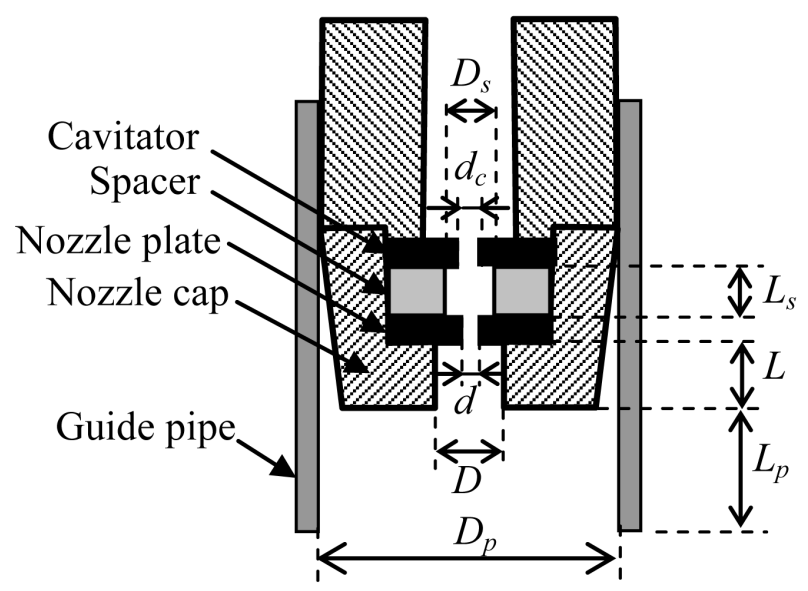

Figure 2. Nozzle for cavitating jet.

\begin{tabular}{ccc} 
Table 1. Gemetry of the nozzle. & & \\
\hline Nozzle diameter & $d$ & $2 \mathrm{~mm}$ \\
Cavitator diameter & $d_{c}$ & $3 \mathrm{~mm}$ \\
Spacer diameter & $D_{s}$ & $6 \mathrm{~mm}$ \\
Spacer length & $L_{s}$ & $6 \mathrm{~mm}$ \\
Outlet bore diameter & $D$ & $16 \mathrm{~mm}$ \\
Oulet bore length & $L$ & $16 \mathrm{~mm}$ \\
Guide pipe diameter & $D_{p}$ & $44 \mathrm{~mm}$ \\
Guide pipe length & $L_{p}$ & $46 \mathrm{~mm}$ \\
\hline
\end{tabular}

Table 2. Cavitating conditions.

\begin{tabular}{ccc}
\hline Injection pressure & $p_{1}$ & $30 \mathrm{MPa}$ \\
Standoff distance & $s$ & $262 \mathrm{~mm}$ \\
\hline
\end{tabular}

The material used in the plate bending fatigue tests was Duralumin Japanese Industrial Standards JIS A2017-T3. The chemical composition and mechanical properties of this are shown in Table 3 and Table 4, respectively. The specimens were each $90 \mathrm{~mm}$ long, $30 \mathrm{~mm}$ wide and $4 \mathrm{~mm}$ thick with a $12 \mathrm{~mm}$ diameter hole at the center, as shown in Figure 3. The holes were carefully drilled by a milling drill with 3 blades using a milling cutter to make the burr as small as possible. The edge was not deburred in order to demonstrate treatment of the sharp edges by cavitation peening.

In these experiments, various cavitating jet flow patterns were considered. Six different experimental set ups were examined as shown in Figure 4. In each case the specimen was placed on a base plate. In Case (a), the specimen was set on a base plate with a $14 \mathrm{~mm}$ diameter hole in it and the nozzle was scanned across the specimen at a constant speed $v$. In Case (b), the specimen was set on a base plate without a hole and scanned. In cases (c) and (d), the specimens were treated for fixed exposure times with a stationary nozzle. The base plates in these cases were open and closed, respectively. In cases (e) and (f), in order to treat the walls of the holes only, a covering plate with a $12 \mathrm{~mm}$ diameter hole was placed on each specimen. In the present experiment, the processing time per unit length, $t_{p}$, is defined by the scanning speed, $v$, and the number of scans, $n$, as follows.

$$
t_{p}=\frac{n}{v}
$$

It has been demonstrated that the effects of cavitation peening, such as improvements in the fatigue strength 
Table 3. Chemical composion of the material under test.

\begin{tabular}{ccccccccc}
\hline $\mathrm{Si}$ & $\mathrm{Fe}$ & $\mathrm{Cu}$ & $\mathrm{Mn}$ & $\mathrm{Mg}$ & $\mathrm{Cr}$ & $\mathrm{Zn}$ & $\mathrm{Ti}$ & $\mathrm{Al}$ \\
\hline 0.68 & 0.53 & 3.8 & 0.46 & 0.56 & 0.01 & 0.09 & 0.15 & $\mathrm{RE}$ \\
\hline
\end{tabular}

Table 4. Mechanical properties of the material under test.

\begin{tabular}{cc} 
Yield stress & $258 \mathrm{MPa}$ \\
Tensile strength & $410 \mathrm{MPa}$ \\
Elongation & $21.7 \%$ \\
\hline &
\end{tabular}

Figure 3. Geometry of the test specimen.

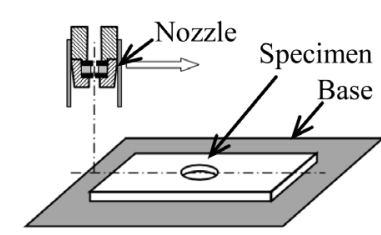

(a) Base plate with hole, scanning jet

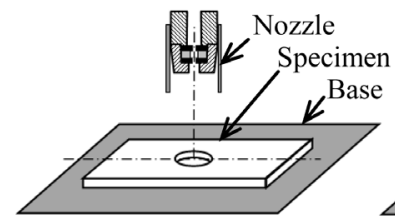

(c) Base plate with hole, fixed jet

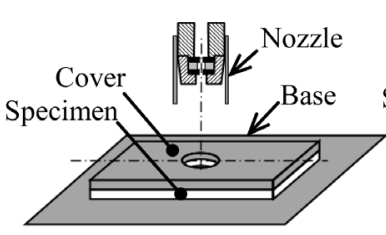

(e) Cover plate, base platewith (f) Cover hole, base plate without hole, scanning jet

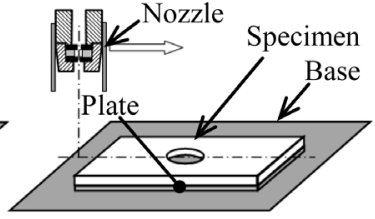

(b) Base plate without hole, scanning jet

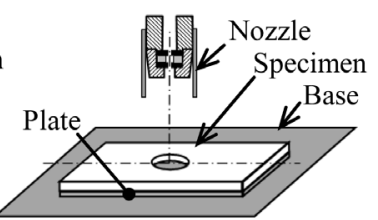
fixed jet

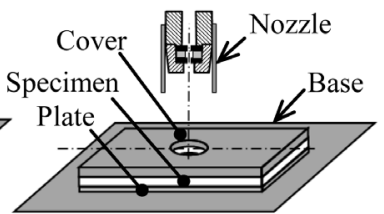

hole, scanning jet (d) Base plate without hole,

\section{Figure 4. Experimental set ups for cavitation peening.}

[20] and suppression of hydrogen embrittlement [21], can be quantified by plate bending fatigue tests. Therefore, a displacement control plate bending fatigue test machine was used to evaluate the fatigue strength of the test specimens in this work.

The residual stress in the walls surrounding the holes and at the surfaces was evaluated by X-ray diffraction. Figure 5 shows the coordinate system used on the specimens. For the case of the walls around the holes, the $\sin ^{2} \psi$ method was used without cutting the specimen. The incident $X$-rays were directed onto the wall from one side of the specimen and the diffracted X-rays were collected from the other side as shown in Figure 6. The residual stresses at the center point, i.e., point $\mathrm{C}$, and $1.5 \mathrm{~mm}$ from the center, i.e., points $\mathrm{A}$ and $\mathrm{B}$, were measured. 


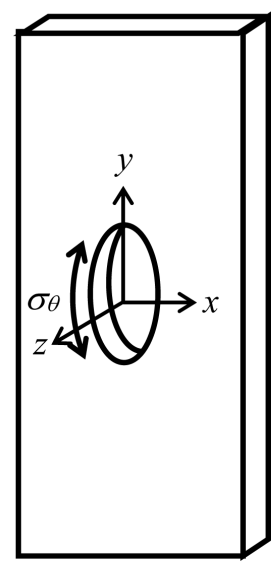

(a) Schematics of specimen

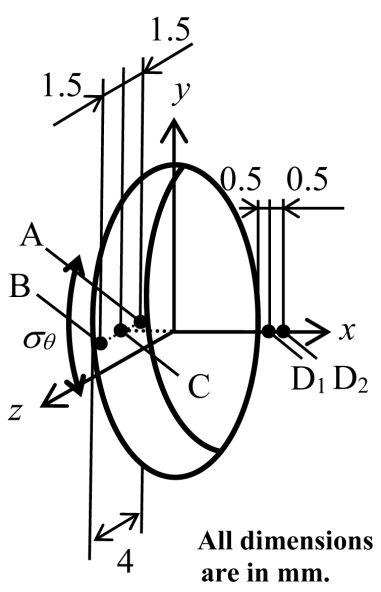

(b) Magnified view

Figure 5. Coordinate system used for the specimen.

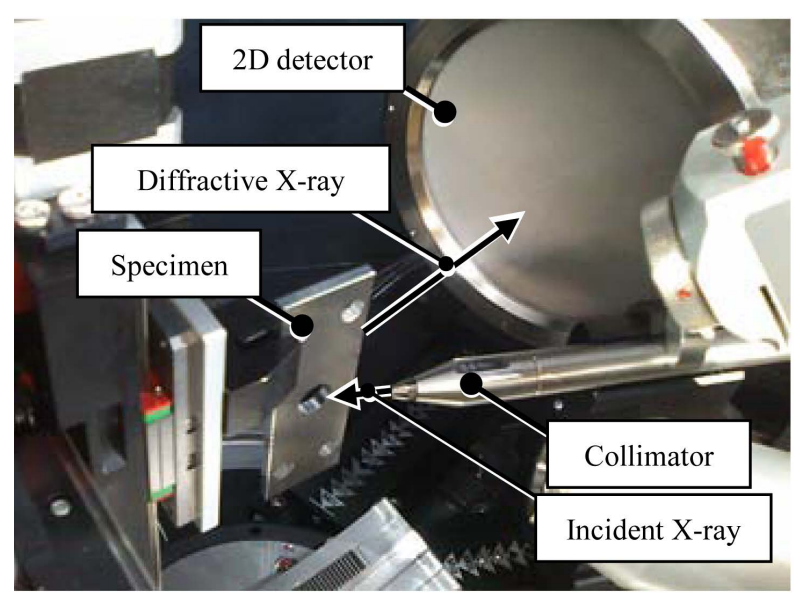

Figure 6. Setup of specimen on XRD system.

The direction of the residual stress in the walls was around the circumference of the hole. For the surface, a 2D method with $\omega$-scanning was used in order to make precise measurements [22]. For both methods, K $\alpha$ $\mathrm{X}$-rays from a tube with a Cr target operated at $35 \mathrm{kV}$ and $40 \mathrm{~mA}$ were used. The X-rays were directed through a $0.8 \mathrm{~mm}$ diameter collimator and an incident monochromator. The lattice plane, (h k l), used was the Al (3 11 ) plane and the diffraction angle without strain was 139 degrees. The diffraction ring from the specimen was detected at several angles using a 2D-PSPC.

\section{Results}

Figure 7 shows apure aluminum surface subjected to a stationary cavitating jet for one minute. A ring with many plastically deformed pits induced by cavitation impact can be observed. The outer and inner diameters of the ring are about $60 \mathrm{~mm}$ and $15 \mathrm{~mm}$, respectively. The cavitation clouds induced by the cavitating jet developed on the surface and then collapsed generating impacts, producing a ring pattern with the region at the center undamaged [23]. The sizes of the large plastically deformed pits are one or two mm in diameter.

Figure 8 shows the results of fatigue tests carried out on peened specimens from the six different set ups shown in Figure 4, and these are compared with the results for a non-peened (NP) specimen. The exposure times for the stationary jets, i.e., (c)-(f), and the processing times per unit length for the scanning jets, i.e., (a) and (b), are shown in the figure. The dotted line in Figure 8 is for the non-peened data and is given by the following equation. 


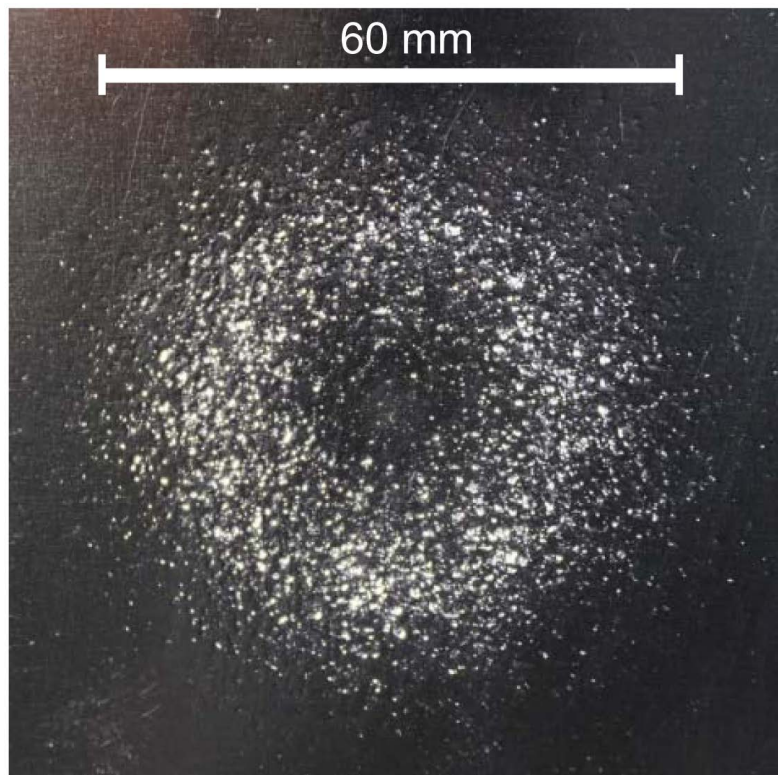

Figure 7. Photograph of pure aluminum surface after cavitation peening.

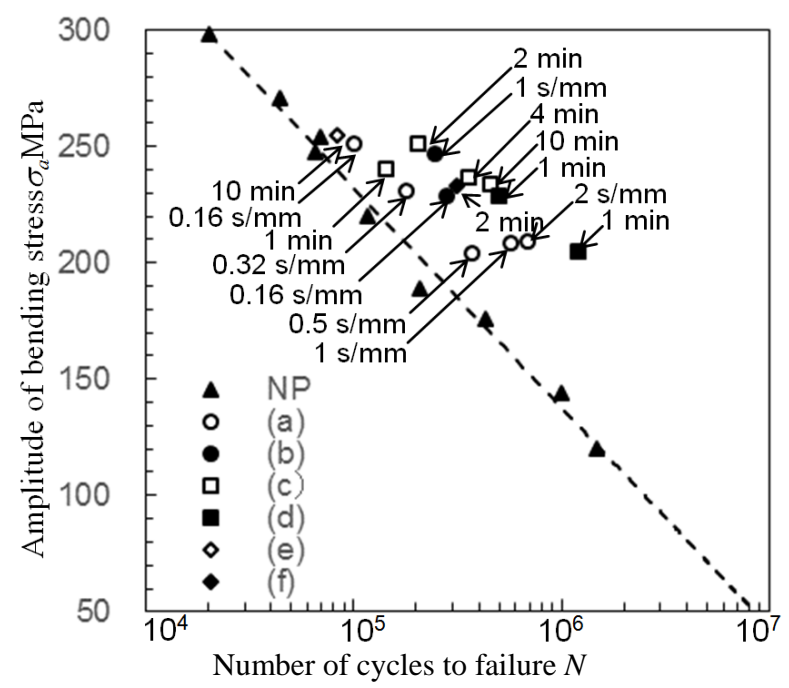

Figure 8. Number of cycles to failure of specimens with and without cavitation peening under various conditions.

$$
\sigma_{a}=-94.45 \log n+704.4
$$

In all cases, the fatigue life was extended by cavitation peening. In order to compare the lifetimes at constant bending stress, the estimated number of cycles to failure $n_{E}$ at $\sigma_{a}=250 \mathrm{MPa}$ was calculated by the following procedure. First, we assumed the slope of the dotted line in Figure 8 can also be applied to the peened specimens. The intercept, $b$, at $n=1$ for each condition was obtained from the bending stress $\sigma_{a}$ and the number of cycles to failure $n$.

$$
b=\sigma_{a}+94.45 \log n
$$

Then $n_{E}$ was obtained using Equation (4).

$$
n_{E}=10^{-\frac{250-b}{94.45}}
$$


Figure 9 shows the variation in the estimated number of cycles to failure, $n_{E}$, at $\sigma_{a}=250 \mathrm{MPa}$ with respect to exposure time, $t_{e}$. In Figure 9, $t_{p}$ is converted to $t_{e}$ as follows. As the outer diameter of the ringregion is about 60 $\mathrm{mm}$ then the peening width is also about $60 \mathrm{~mm}$; thus, a processing time per unit length $t_{p}=1 \mathrm{~s} / \mathrm{mm}$, equivalent to $60 \mathrm{~mm} / \mathrm{min}$, corresponds to $t_{e}=1$ minute. $n_{E}$ for the non-peened specimen is 64,748 as shown by the arrow in Figure 9. $n_{E}$ for all the peened specimens is larger than the non-peened one. For each experimental condition, $n_{E}$ generally increases with $t_{e}$. The closed symbols are generally placed higher than the open symbols, signifying that the fatigue strength is increased by using a base plate without a hole. When a base plate with a hole is used, many of the cavitation bubbles pass through the hole. On the other hand, without a hole in the base plate, the cavitation bubbles collapse on the surface of the base plate and on the wall of the hole. $n_{E}$ for the covered specimens, (e) and (f), is 92,700 and 210,223, respectively. This means that, compared with the non-peened specimen, cavitation peening has improved the fatigue life by factors of 1.4 and 3.2, respectively. These results suggest that a cavitating jet parallel to the wall around the hole can be used to treat the surface of the wall.

For practical applications a scanning jet is used, since the overall surface, as well as the fastener hole, can be peened. Thus, a scanning jet and a base plate without a hole, i.e., as in Figure 4(b), were chosen for the fatigue test to obtain the fatigue strength. One side of the specimen was treated first, followed by the other. The processing time per unit length, $t_{p}$, was set to $1 \mathrm{~s} / \mathrm{mm}$. As is well known, a peened surface becomes convex after peening. With $t_{p}=1 \mathrm{~s} / \mathrm{mm}$, the arc height was too large for the specimen, when turned over to treat the other side, to be fixed to a flat plate without the possibility of plastically deforming the specimen. In order to minimize plastic deformation of the specimen, the front side was scanned first at $v=2 \mathrm{~mm} / \mathrm{s}$, i.e., $t_{p}=0.5 \mathrm{~s} / \mathrm{mm}$, followed by scanning of the back side at $v=1 \mathrm{~mm} / \mathrm{s}$, i.e., $t_{p}=1 \mathrm{~s} / \mathrm{mm}$, and finally further scanning of the front side at $v=$ $2 \mathrm{~mm} / \mathrm{s}$. In this process, the maximum difference between the processing times per unit length between the front and back sides was $0.5 \mathrm{~s} / \mathrm{mm}$; with these conditions, plastic deformation of the specimen when fixing it to the base plate could be avoided. After the process, both sides were treated by cavitation peening at $t_{p}=1 \mathrm{~s} / \mathrm{mm}$.

Figure 10 illustrates the relationship between the amplitude of the bending stress and the number of cycles to failure for the non-peened and cavitation peened specimens, which shows that cavitation peening has improved the fatigue life. As shown in Figure 10, although the non-peened specimen with $\sigma_{a}=120.1$ MPa broke after $1.48 \times 10^{6}$ cycles, the cavitation peened specimen with $\sigma_{a}=164.1$ MPa survived for $10^{7}$ cycles.

Using Little's method [24], the fatigue strength of the non-peened specimen for $10^{7}$ cycles is $113.5 \mathrm{MPa}$ and that of the cavitation peened specimen is $171.0 \mathrm{MPa}$. That is, cavitation peening has improved the fatigue strength by $51 \%$.

In order to investigate the mechanism by which the fatigue strength is improved by cavitation peening, Figure 11 shows photographs of the surface around the hole. On the surface of the cavitation peened specimen, many plastic deformation pits can be seen around the hole. These pits introduce compressive residual stress. The sizes of the large pits are between 1 and $2 \mathrm{~mm}$ in diameter as shown in Figure 11(b). Figure 12 and Figure 13 show the fracture surfaces of the non-peened and cavitation peened specimens, respectively. Figure 12(a) and Figure 13(a)

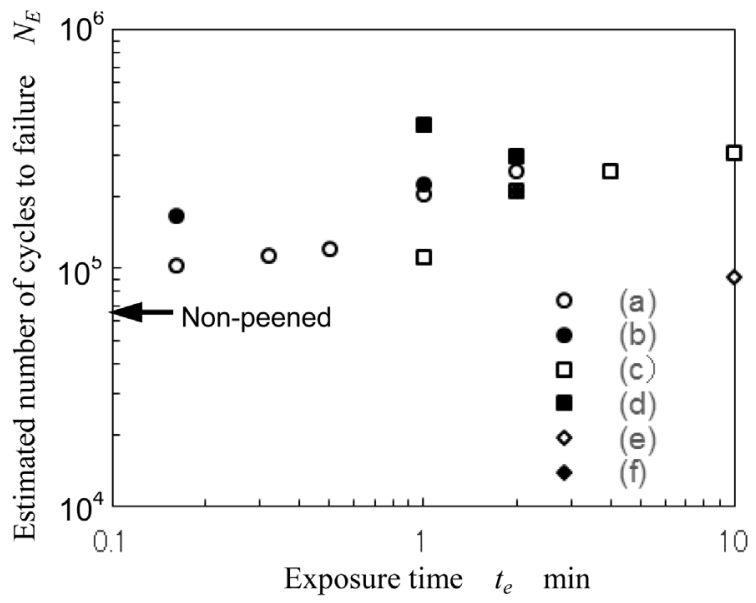

Figure 9. Variation of the number of cycles to failure at $\sigma_{a}=$ $250 \mathrm{MPa}$ with exposure time. 


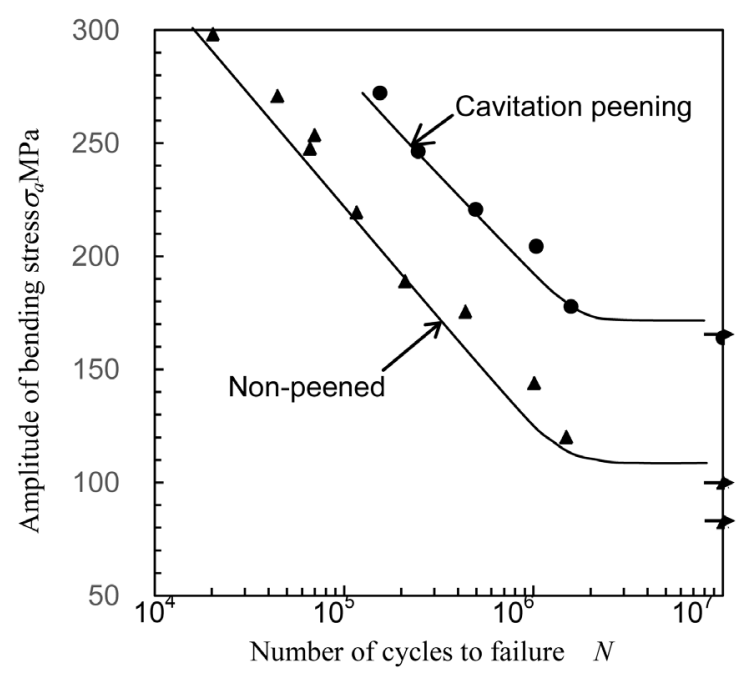

Figure 10. Improvement in the fatigue strength by cavitation peening using the conditions shown in Figure 4(b).

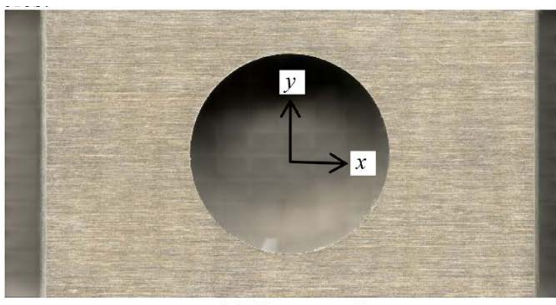

(a) Non-peened

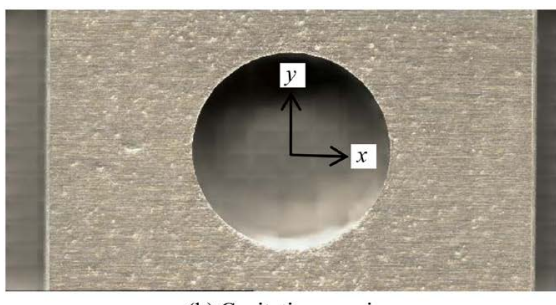

(b) Cavitation peening

Figure 11. Photographs of surface around the hole before the plate bending fatigue test.

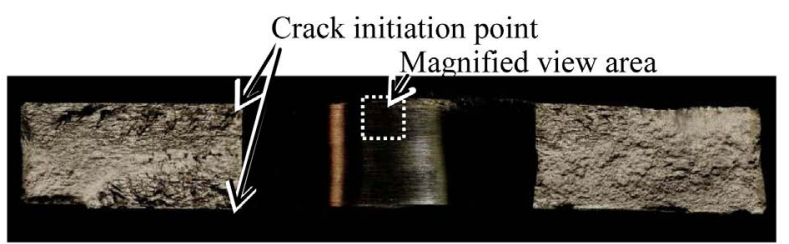

(a) Overall view

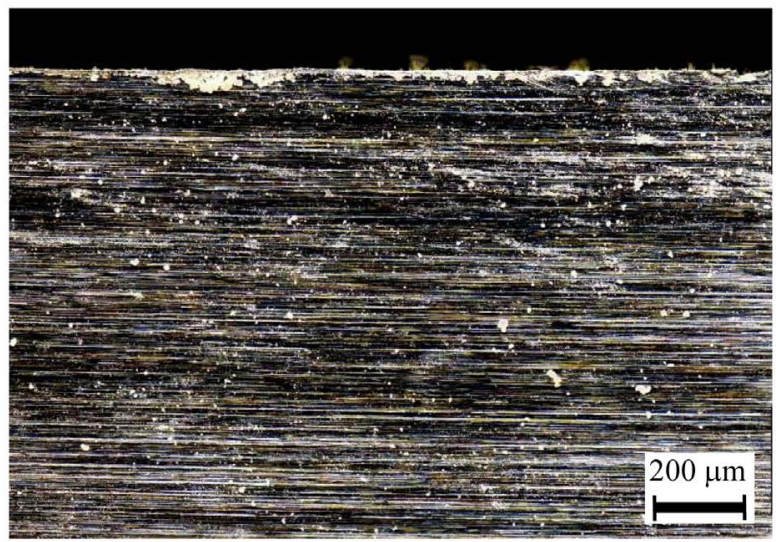

(b) Close up view

Figure 12. Photographs of the fracture surface and inside the hole of the non-peened specimen $\left(\sigma_{a}=175.7 \mathrm{MPa}\right)$. 


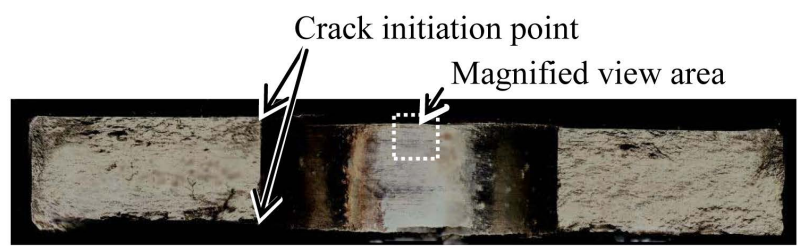

(a) Overall view

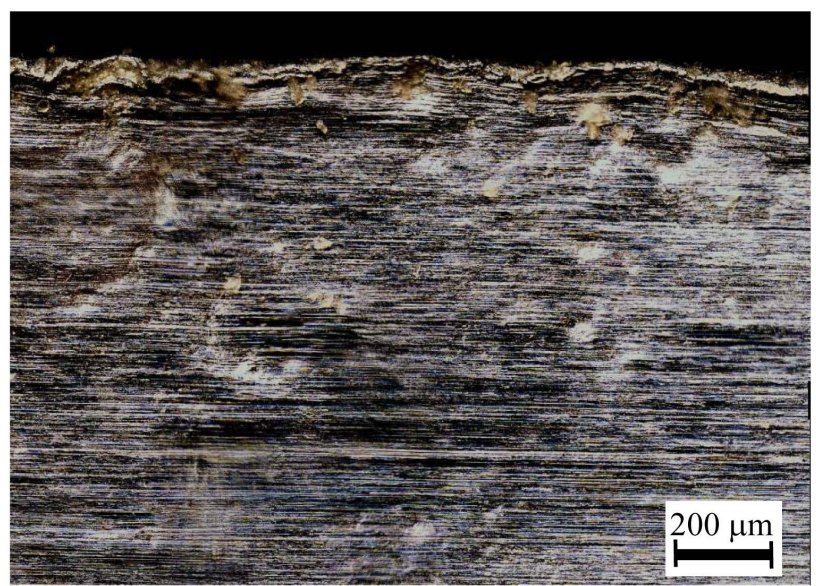

(b) Close up view

Figure 13. Photographs of the fracture surface and inside the hole of the cavitation peened specimen $\left(\sigma_{a}=177.9 \mathrm{MPa}\right)$.

show overall views and Figure 12(b) and Figure 13(b) show close ups of the inner surfaces of the holes. For both the non-peened and cavitation peened specimens, the cracks begin at the edges of the hole on the surface, where the maximum bending stress occurs. Also, as shown in Figure 12(b), plastic deformation pits can be seen on the walls of the hole. This means that the cavitating jet has treated the surface parallel to the jet axis. However, the sizes of the pits on the wall surrounding the hole are a few hundred micrometers in diameter, somewhat smaller than those on the surface.

Figure 14 shows the residual stress, $\sigma_{R}$, on the surface of the non-peened and cavitation peened specimens. The direction of the residual stress in Figure 14 is in the longitudinal direction of the specimen, i.e., the $y$-direction, as the tensile stress in the plate bending fatigue test was applied in this direction. In the case of the non-peened specimen, $\sigma_{R}$ varies from about -35 to $-70 \mathrm{MPa}$. On the other hand, $\sigma_{R}$ for the cavitation peened specimen varies from about -170 to $-230 \mathrm{MPa}$. Thus, cavitation peening has increased the compressive residual stress by more than $100 \mathrm{MPa}$. The compressive residual stress of the cavitation peened specimen near the hole is somewhat larger than at the edge of the specimen.

Figure 15 shows the residual stress, $\sigma_{\theta}$, in the surface of the wall around the hole before and after peening. $\sigma_{\theta}$ before peening varies between about -20 and $-120 \mathrm{MPa}$. After peening, $\sigma_{\theta}$ is about $-200 \mathrm{MPa}$. Thus, cavitation peening has increased the compressive residual stress by about $100 \mathrm{MPa}$. We conclude, therefore, that increasing the compressive residual stress at the surface and in the wall surrounding the hole enhances the fatigue strength.

\section{Conclusions}

In order to demonstrate that the fatigue strength around fastener holes in aircraft components can be improved by cavitation peening, specimens of Duralumin plates with holes were treated by cavitation peening and the fatigue strength was evaluated using a plate bending fatigue test. The residual stresses on the surface and in the wall surrounding the hole were measured by X-ray diffraction. The main results obtained can be summarized as follows.

1) The fatigue life of a Duralumin plate with a hole in it was improved by cavitation peening. The degree of im- 


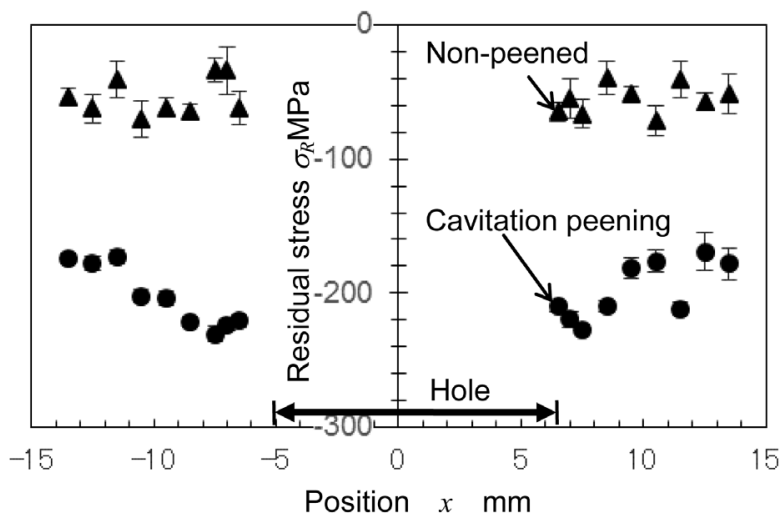

Figure 14. Residual stress at the surface.

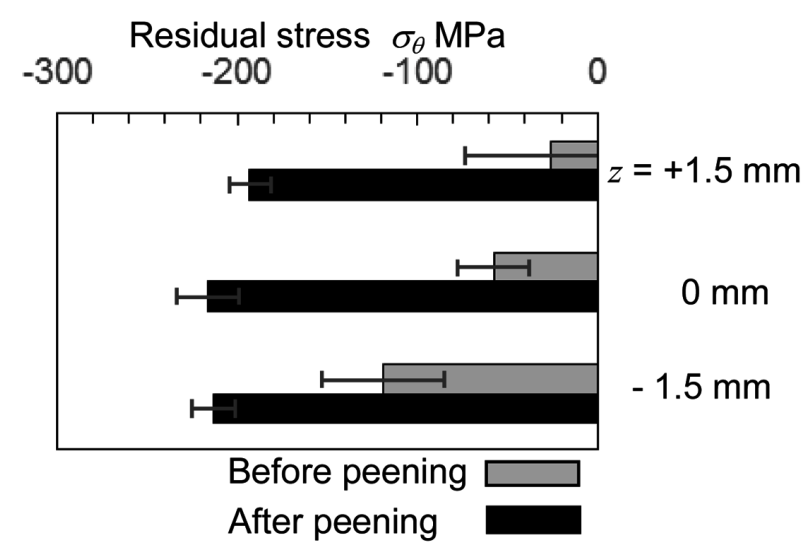

Figure 15. Residual stress in the wall surrounding the hole.

provement in the lifetime depended on the flow pattern used for the cavitating jet. For equal exposure times to the jet, the improvement when a base plate without a hole was used was much larger than when a base plate with a hole was used.

2) In the present experiments, cavitation peening increased the fatigue strength of a Duralumin plate with a hole by $51 \%$.

3) Cavitation peening can be used to introduce a compressive residual stress both into the surface of the plate and into the wall surrounding the hole. The compressive residual stress was increased by about $100 \mathrm{MPa}$ using the present conditions.

\section{Acknowledgements}

This work was partly supported by JSPS KAKENHI Grant Number 24360040 and The Amada Foundation. The authors thank Mr. M. Mikami, technician, Tohoku University for his help with the experiments.

\section{References}

[1] Phillips, J.L. (1973) Fatigue Improvement by Sleeve Cold Working. SAE Technical Paper 730905.

[2] Yang, J.M., Her, Y.C., Han, N.L. and Clauer, A. (2001) Laser Shock Peening on Fatigue Behavior of 2024-T3 Al Alloy with Fastener Holes and Stopholes. Materials Science and Engineering A-Structural Materials Properties Microstructure and Processing, 298, 296-299. http://dx.doi.org/10.1016/S0921-5093(00)01277-6

[3] Tan, Y., Wu, G., Yang, J.M. and Pan, T. (2004) Laser Shock Peening on Fatigue Crack Growth Behaviour of Aluminium Alloy. Fatigue \& Fracture of Engineering Materials \& Structures, 27, 649-656. http://dx.doi.org/10.1111/j.1460-2695.2004.00763.x

[4] Ivetic, G., Meneghin, I., Troiani, E., Molinari, G., Ocana, J., Morales, M., Porro, J., Lanciotti, A., Ristori, V., Polese, 
C., Plaisier, J. and Lausi, A. (2012) Fatigue in Laser Shock Peened Open-Hole Thin Aluminium Specimens. Materials Science and Engineering A-Structural Materials Properties Microstructure and Processing, 542, 147-147. http://dx.doi.org/10.1016/j.msea.2012.02.037

[5] Cuellar, S.D., Hill, M.R., DeWald, A.T. and Rankin, J.E. (2012) Residual Stress and Fatigue Life in Laser Shock Peened Open Hole Samples. International Journal of Fatigue, 44, 8-13. http://dx.doi.org/10.1016/j.ijfatigue.2012.06.011

[6] Brennen, C.E. (1995) Cavitation and Bubble Dynamics. Oxford University Press, Oxford.

[7] Soyama, H., Kusaka, T. and Saka, M. (2001) Peening by the Use of Cavitation Impacts for the Improvement of Fatigue Strength. Journal of Materials Science Letters, 20, 1263-1265. http://dx.doi.org/10.1023/A:1010947528358

[8] Soyama, H., Saito, K. and Saka, M. (2002) Improvement of Fatigue Strength of Aluminum Alloy by Cavitation Shotless Peening. Journal of Engineering Materials and Technology, 124, 135-139. http://dx.doi.org/10.1115/1.1447926

[9] Odhiambo, D. and Soyama, H. (2003) Cavitation Shotless Peening for Improvement of Fatigue Strength of Carbonized Steel. International Journal of Fatigue, 25, 1217-1222. http://dx.doi.org/10.1016/S0142-1123(03)00121-X

[10] Soyama, H., Yamauchi, Y., Adachi, Y., Sato, K., Shindo, T. and Oba, R. (1995) High-Speed Observations of the Cavitation Cloud around a High-Speed Submerged Water-Jet. JSME International Journal Series B-Fluids and Thermal Engineering, 38, 245-251. http://dx.doi.org/10.1299/jsmeb.38.245

[11] Soyama, H., Yamauchi, Y., Sato, K., Ikohagi, T., Oba, R. and Oshima, R. (1996) High-Speed Observation of Ultrahigh-Speed Submerged Water Jets. Experimental Thermal and Fluid Science, 12, 411-416. http://dx.doi.org/10.1016/0894-1777(95)00124-7

[12] Soyama, H., Shimizu, M., Hattori, Y. and Nagasawa, Y. (2008) Improving the Fatigue Strength of the Elements of a Steel Belt for CVT by Cavitation Shotless Peening. Journal of Materials Science, 43, 5028-5030. http://dx.doi.org/10.1007/s10853-008-2743-6

[13] Soyama, H., Macodiyo, D.O. and Mall, S. (2004) Compressive Residual Stress into Titanium Alloy Using Cavitation Shotless Peening Method. Tribology Letters, 17, 501-504. http://dx.doi.org/10.1023/B:TRIL.0000044497.45014.f2

[14] Lee, H., Mall, S. and Soyama, H. (2009) Fretting Fatigue Behavior of Cavitation Shotless Peened Ti-6Al-4V. Tribology Letters, 36, 89-94. http://dx.doi.org/10.1007/s11249-009-9463-1

[15] Soyama, H., Nagasaka, K., Takakuwa, O. and Naito, A. (2012) Optimum Injection Pressure of a Cavitating Jet for Introducing Compressive Residual Stress into Stainless Steel. Journal of Power and Energy Systems, 6, 63-75. http://dx.doi.org/10.1299/jpes.6.63

[16] Daniewicz, S.R. and Cummings, S.D. (1999) Characterization of a Water Peening Process. Journal of Engineering Materials and Technology-Transactions of the ASME, 121, 336-340. http://dx.doi.org/10.1115/1.2812383

[17] Chillman, A., Ramulu, M. and Hashish, M. (2007) Waterjet Peening and Surface Preparation at 600 MPa: A Preliminary Experimental Study. Journal of Fluids Engineering-Transactions of the ASME, 129, 485-490. http://dx.doi.org/10.1115/1.2436580

[18] Soyama, H. (2014) Enhancing the Aggressive Intensity of a Cavitating Jet by Introducing a Cavitator and a Guide Pipe. Journal of Fluid Science and Technology, 9, 1-12. http://dx.doi.org/10.1299/jfst.2014jfst0001

[19] Soyama, H. (2011) Corrosion Behavior of Pressure Vessel Steel Exposed to Residual Bubbles after Cavitation Bubble Collapse. Corrosion, 67, 025001-1-025001-8. http://dx.doi.org/10.5006/1.3548733

[20] Soyama, H. (2007) Improvement of Fatigue Strength by Using Cavitating Jets in Air and Water. Journal of Materials Science, 42, 6638-6641. http://dx.doi.org/10.1007/s10853-007-1535-8

[21] Takakuwa, O. and Soyama, H. (2012) Suppression of Hydrogen-Assisted Fatigue Crack Growth in Austenitic Stainless Steel by Cavitation Peening. International Journal of Hydrogen Energy, 37, 5268-5276. http://dx.doi.org/10.1016/j.ijhydene.2011.12.035

[22] Takakuwa, O. and Soyama, H. (2013) Optimizing the Conditions for Residual Stress Measurement Using a Two-Dimensional XRD Method with Specimen Oscillation. Advances in Materials Physics and Chemistry, 3, 8-18. http://dx.doi.org/10.4236/ampc.2013.31A002

[23] Soyama, H., Park, J.D. and Saka, M. (2000) Use of Cavitating Jet for Introducing Compressive Residual Stress. Journal of Manufacturing Science and Engineering-Transactions of the ASME, 122, 83-89. http://dx.doi.org/10.1115/1.538911

[24] Little, R.E. (1972) Estimating the Median Fatigue Limit for Very Small Up-and-Down QuantalResponse Tests and for S-N Data with Runouts. ASTM STP, 511, 29-42. 